\title{
A self-assembling matrix-forming gel can be easily and safely applied to prevent delayed bleeding after endoscopic resections
}

Authors

Institutions
Mathieu Pioche ${ }^{1,2,3}$, Marine Camus ${ }^{4,5}$, Jérôme Rivory ${ }^{1}$, Sarah Leblanc ${ }^{4}$, Isabelle Lienhart ${ }^{1}$, Maximilien Barret ${ }^{4,5}$, Stanislas Chaussade ${ }^{4,5}$, Jean-Christophe Saurin ${ }^{1,3}$, Frederic Prat ${ }^{4,5}$, Thierry Ponchon ${ }^{1,2,3}$

Institutions are listed at the end of article. submitted

4. November 2015 accepted after revision 29. January 2016

\section{Bibliography}

DOI http://dx.doi.org/

10.1055/s-0042-102879

Published online: 30.3.2016

Endoscopy International Open

2016; 04: E415-E419

(c) Georg Thieme Verlag KG

Stuttgart · New York

E-ISSN 2196-9736

\section{Corresponding author}

\section{Mathieu Pioche}

Endoscopy Unit

Digestive Disease Department

Pavillon L - Edouard Herriot

Hospital

69437 Lyon Cedex

France

Fax: +33-4-72110147

mathieu.pioche@chu-lyon.fr
Background: Endoscopic resections have low morbidity and mortality. Delayed bleeding has been reported in approximately $1-15 \%$ of cases, increasing with antiplatelet/anticoagulant therapy or portal hypertension. A self-assembling peptide (SAP) forming a gel could protect the mucosal defect during early healing. This retrospective trial aimed to assess the safety and efficacy of SAP in preventing delayed bleeding after endoscopic resections.

Methods: Consecutive patients with endoscopic resections were enrolled in two tertiary referral centers. Patients with a high risk of bleeding (antiplatelet agents, anticoagulation drugs with heparin bridge therapy, and cirrhosis with portal hypertension) were also included. The SAP gel was applied immediately after resection to cover the whole ulcer bed.

Results: In total, 56 patients were included with 65 lesions (esophagus [n=8], stomach $[n=22]$, duodenum [ $\mathrm{n}=10]$, ampullary $[\mathrm{n}=3]$, colon $[\mathrm{n}=$ 7], and rectum [n=15]) in two centers. Among those 65 lesions, 29 were resected in high risk si-

\section{Introduction}

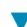

Endoscopic resections including endoscopic mucosal resection (EMR) and endoscopic submucosal dissection (ESD) can remove superficial digestive neoplasia with low morbidity and mortality. Nevertheless, delayed bleeding has been reported as approximately $0 \%$ in the esophagus [1], $5 \%$ in the stomach [2], 20\% in the duodenum [3], and 2 $\%$ in the colorectum [4] increasing with antiplatelet/anticoagulant therapy $[2,5]$ or in cases with portal hypertension $[6,7]$. In the specific duodenal condition, the bleeding risk is clearly associated with a lesion size over 2 or $3 \mathrm{~cm}[3,8]$.

Thus, reducing the rate of delayed bleeding in high risk situations remains a challenge, and mechanical protection of the ulcer bed seems an interesting approach to cover the muscle and to tuations (9 uninterrupted aspirin therapy, 6 heparin bridge therapies, 5 cirrhosis and portal hypertension, 1 both cirrhosis and heparin bridge, 3 both cirrhosis and uninterrupted aspirin, 3 large duodenal lesions $>2 \mathrm{~cm}$, and 2 early introduction of clopidogrel at day 1 ). The resection technique was endoscopic submucosal dissection (ESD) in 40 cases, en bloc endoscopic mucosal resection (EMR) in 16, piecemeal EMR in 6, and ampullectomy in 3. The mean lesion size was $37.9 \mathrm{~mm}$ (SD: $2.2 \mathrm{~mm}$ ) with a mean area of $6.3 \mathrm{~cm}^{2}$ (SD: $3.5 \mathrm{~cm}^{2}$ ). No difficulty was noted during application. Four delayed overt bleedings occurred (6.2\%) (3 hematochezia, 1 hematemesis) requiring endoscopic hemostasis. The mean hemoglobin drop off was $0.6 \mathrm{~g} / \mathrm{dL}$ ( -0.6 to $3.1 \mathrm{~g} / \mathrm{dL}$ ). No adverse events occurred.

Conclusion: The use of this novel extracellular matrix scaffold may help to reduce post-endoscopic resection bleedings including in high risk situations. Its use is easy and safe but further comparative studies are warranted to completely evaluate its effectiveness.

prevent chemical lesions induced by gastric or bile secretions in the upper gastrointestinal tract and stools in the lower gastrointestinal tract. Such a protective effect was previously demonstrated with clip closure but this strategy is expensive and time consuming $[9,10]$. A self-assembling peptide (SAP) forming a gel under appropriate conditions of ionization could protect the mucosal defect during the early phase of healing and could also prevent stenosis [11]. The aim of the present clinical trial was to assess the safety and efficacy of a newly developed SAP called Purastat ${ }^{\circledR}$ (3 D Matrix, Ltd, Tokyo, Japan) to prevent delayed bleeding after endoscopic resections including in high risk patients. 

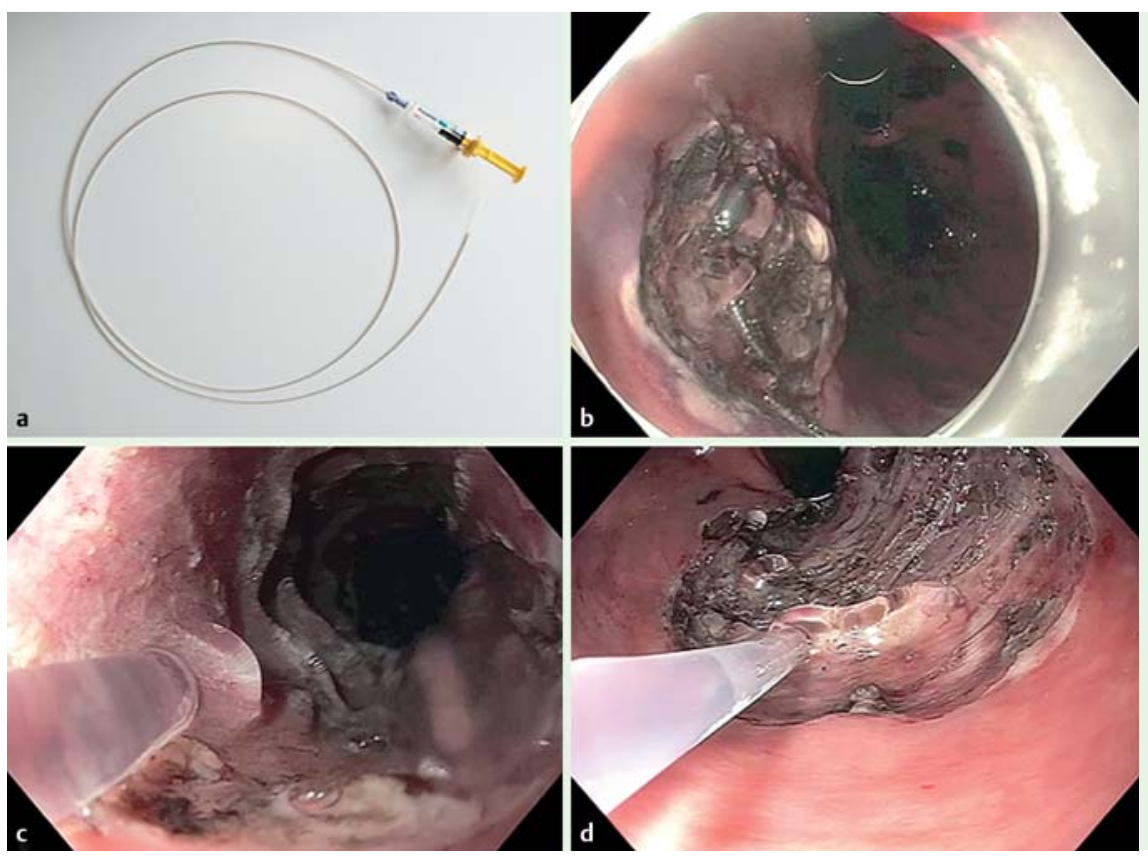

Fig. 1 Presentation of the Purastat ${ }^{\circledR}$ device in different locations of the digestive tract. a Device with syringe and catheter. $\mathbf{b}$ Completion of coverage. c Application in the esophagus in direct viewing. $\mathbf{d}$ Application in the rectum in retroflexed position of the scope.
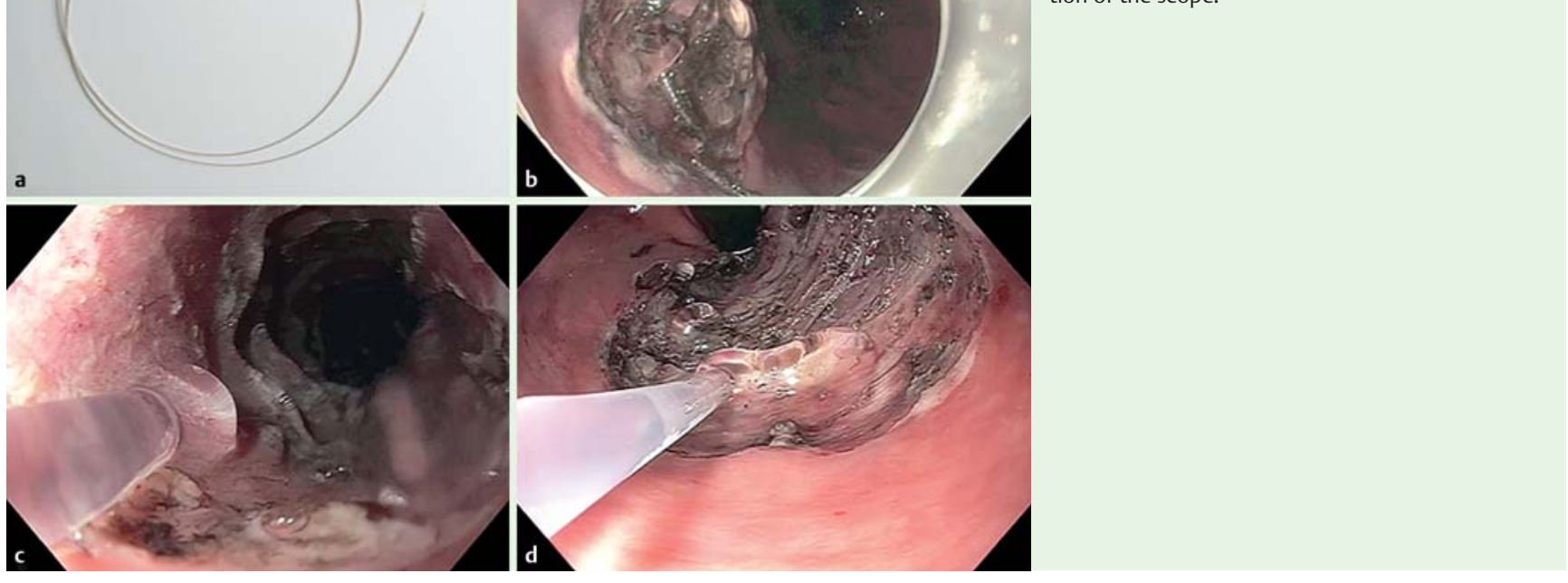

\section{Materials and methods}

$\nabla$

Consecutive patients in the two university centers who were referred for endoscopic resections (EMR or ESD) for esophageal, gastric, duodenal or colonic superficial lesions were informed of the possibility of gel use and gave their oral consent before the procedure. High risk patients were defined as follows: uninterrupted acetylsalicylic acid treatment [12], anticoagulation drugs with heparin bridge therapy, large duodenal resections over 2 $\mathrm{cm}$, and liver cirrhosis with portal hypertension and varices.

SAP was available for use in the endoscopic units of both university centers between July 2014 and June 2015. SAP has the CE (European Conformity) mark and has been available for use in humans since $2014[13,14]$. We retrospectively reviewed and recorded data on all patients who underwent gel application during this period.

Purastat ${ }^{\circledR}$ is a fully synthetic matrix scaffold with the CE mark and can be applied with an endoscopic catheter. Two different dedicated 2.8-mm diameter catheters were used measuring $1800 \mathrm{~mm}$ for upper gastrointestinal scopes and $2200 \mathrm{~mm}$ for colonoscopes (Purastat Nozzle System type E, Top Corporation, Tokyo, Japan). Purastat ${ }^{\circledR}$ is a peptide solution that self assembles at physiological pH and forms a gel comprising a network of nanofibers. Its benefits in hemostasis and its biocompatibility have previously been demonstrated in different animal models including bones, kidney, and nerves $[13,15,16]$. It was also used in humans for hemostasis of gastric tumors without toxicity [14]. When the gel comes into contact with blood or tissue fluids, the change in $\mathrm{pH}$ and salt concentration causes fiber formation and gelation that block the blood vessels in the hemorrhagic area and generate the hemostatic effects [14]. Furthermore, contact between the gel and the mucosal wound is supposed to make an adhesion facilitating fixation of the nanofiber network against gravity.

Using a dedicated catheter, an adequate volume of gel was applied (using 3- or 5-mL syringes) to cover the whole resected area immediately after the end of the endoscopic procedure. Careful application of the gel to the full resected area was performed as shown in $\bullet$ Fig. 1. If the whole resected bed was not totally covered, the endoscopist could use a second syringe to complete the coverage. Subsequent patient management included oral proton pump inhibitors (PPIs) after esophageal, gastric, or duodenal resection was performed following local protocols. The primary end point was the rate of post-resection bleeding in the month following the resection evaluated by the overt bleeding and the hemoglobin drop off at day 1 after the procedure. Postresection bleeding was defined by a post-procedural overt hemorrhage: hematemesis, hematochezia or melena with or without systemic consequences (hypotension, tachycardia) requiring or not requiring a second-look endoscopy procedure for hemostasis. Duration of the application, ease of use, and safety were also assessed.

\section{Statistics}

An Excel ${ }^{\circledR}$ spreadsheet (Microsoft, United States) was used to complete the report form prospectively. Anonymized data were collected and analyzed retrospectively using descriptive statistics for quantitative variables and qualitative variables.

\section{Results \\ $\nabla$}

In total, 56 patients ( 34 males, 22 females, mean age: 66.9 years, SD: 11.4 years) were included with 65 lesions from different locations in the digestive tract ( Table 1 ) (esophagus $(\mathrm{n}=8)$, stomach $(n=22)$, duodenum $(n=10)$, ampullary $(n=3)$, colon $(n=7)$, and rectum $(n=15)$ ) in two tertiary care centers in Lyon (33 patients, 39 lesions) and Paris (23 patients, 26 lesions).

Among those 65 lesions, 29 (44.6\%) were resected in high risk situations: 9 uninterrupted aspirin therapy, 6 heparin bridge therapies followed by anticoagulant drugs at day 1, 5 cirrhosis and portal hypertension, 1 both cirrhosis and heparin bridge therapy, 3 both cirrhosis and uninterrupted aspirin therapy, 3 large duodenal lesions $>2 \mathrm{~cm}$, and 2 early introduction of clopidogrel at day 1 .

The resection technique ( $\bullet$ Table 2 ) was an ESD in 40 cases, an en bloc EMR in 16, a piecemeal EMR in 6 cases, and an ampullectomy in 3 cases. The mean size of the resected specimen was $37.9 \mathrm{~mm}$ (SD: $2.2 \mathrm{~mm}$ ) with a mean area of $6.3 \mathrm{~cm}^{2}\left(\mathrm{SD}: 3.5 \mathrm{~cm}^{2}\right)$. 
Table 1 Overall results from the different locations in the digestive tract.

\begin{tabular}{|c|c|c|c|c|c|c|c|c|}
\hline Histology & Number & $\begin{array}{l}\text { Diameter, } \\
\text { mean } \\
\text { (SD), cm }\end{array}$ & $\begin{array}{l}\text { Area } \\
\text { mean (SD), } \\
\mathrm{cm}^{2}\end{array}$ & $\begin{array}{l}\text { Bleeding, } \\
\text { n (\%) }\end{array}$ & $\begin{array}{l}\text { Hb drop off, } \\
\text { g/dL }\end{array}$ & $\begin{array}{l}\text { Adverse } \\
\text { events, } n\end{array}$ & $\begin{array}{l}\text { Volume, } \\
\text { mean, (SD), } \\
\mathrm{mL}\end{array}$ & $\begin{array}{l}\text { Time, mean } \\
\text { (SD), min }\end{array}$ \\
\hline Esophagus & 8 & $4.8(2.7)$ & $7.9(3.4)$ & $2(25 \%)$ & $0.7(0.9)$ & 0 & $3.8(1.2)$ & $2(1.0)$ \\
\hline SCC & 2 & & & $1(50 \%)$ & & & & \\
\hline Barrett & 5 & & & $0(0 \%)$ & & & & \\
\hline Papilloma & 1 & & & $1(100 \%)$ & & & & \\
\hline Stomach & 22 & $3.8(1.8)$ & $5.9(3.1)$ & $0(0 \%)$ & $0.3(0.5)$ & 0 & $3.6(1.5)$ & $2.1(1.2)$ \\
\hline Hyperplastic & 4 & & & 0 & & & & \\
\hline LGD & 3 & & & 0 & & & & \\
\hline HGD & 8 & & & 0 & & & & \\
\hline ADK & 6 & & & 0 & & & & \\
\hline Endocrine & 1 & & & 0 & & & & \\
\hline $\begin{array}{l}\text { Duodenum } \\
\text { adenoma }\end{array}$ & 10 & $2.8(2.0)$ & $5.0(3.3)$ & $0(0 \%)$ & DM & 0 & $4.1(1.2)$ & $2.5(1.7)$ \\
\hline Ampullary tumor & 3 & $2.0(0.9)$ & $3.2(0.9)$ & $1(33.3 \%)$ & $1.25(1.2)$ & 0 & $3(0)$ & $1(0)$ \\
\hline Colon adenoma & 7 & $2.9(1.2)$ & $5.3(2.5)$ & $0(0 \%)$ & $0.9(0.8)$ & 0 & $2.1(0.9)$ & $1.6(0.6)$ \\
\hline Rectum adenoma & 15 & $4.8(2.5)$ & $8.3(4.3)$ & $1(6.7 \%)$ & $0.7(0.9)$ & 0 & $3.9(1.5)$ & $1.8(1.1)$ \\
\hline Total & 65 & $3.8(2.2)$ & $6.3(3.5)$ & $4(6.2)$ & $0.6(0.8)$ & 0 & $3.5(1.4)$ & $2.0(1.1)$ \\
\hline
\end{tabular}

SCC, squamous cell carcinoma; Hb, hemoglobin; HGD, high grade dysplasia; LGD, low grade dysplasia; ADK, adenocarcinoma; SD, standard deviation.

Table 2 Results depending on the resection technique.

\begin{tabular}{|c|c|c|c|c|}
\hline & $\operatorname{ESD}(n=40)$ & Piecemeal EMR $(n=6)$ & Ampullectomy $(n=3)$ & $\operatorname{EMR}(n=16)$ \\
\hline \multicolumn{5}{|l|}{ Center } \\
\hline Lyon & 31 & 1 & 0 & 7 \\
\hline Paris & 9 & 5 & 3 & 9 \\
\hline \multicolumn{5}{|l|}{ Location in digestive tract } \\
\hline Esophagus & 6 & 1 & - & 1 \\
\hline Stomach & 19 & - & - & 3 \\
\hline Duodenum & - & 4 & - & 6 \\
\hline Ampullary & - & - & 3 & - \\
\hline Colon & 3 & 1 & - & 3 \\
\hline Rectum & 12 & - & - & 3 \\
\hline Main diameter, mean (SD), cm & $4.5(2.3)$ & $4.4(1.4)$ & $1.9(0.9)$ & $2.1(1.2)$ \\
\hline Area, mean (SD), $\mathrm{cm}^{2}$ & $7.3(3.7)$ & $8.0(2.0)$ & $3.2(0.9)$ & $3.8(2.0)$ \\
\hline Purastat volume, mean (SD), mL & $3.6(1.5)$ & $3.7(1.0)$ & $3(0)$ & $3.2(1.4)$ \\
\hline Bleeding, number (\%) & $2(5.0)$ & $0(0)$ & $1(33.3)$ & 1 \\
\hline Hemoglobin drop-off, mean (SD), g/dL & $0.6(0.8)$ & $0.6(0.8)$ & $1.25(1.2)$ & $0.5(0.7)$ \\
\hline
\end{tabular}

ESD, endoscopic submucosal dissection; EMR, endoscopic mucosal resection.

After all the resections, the resection bed was carefully examined and prophylactic hemostasis of the visible vessels was performed with diathermic forceps in 41 cases or with the tip of the snare in 4 cases. Among the 65 resections, 14 clips were put on superficial muscular injuries to prevent delayed perforations but without closure of the resection bed.

\section{Delayed bleeding}

There were four delayed overt bleedings on the 65 resected areas (6.2\%) (3 hematochezia, 1 hematemesis) requiring endoscopic hemostasis in four cases. One occurred after ampullectomy and was treated with Hemospray ${ }^{\circledR}$, and one occurred after rectal ESD in a high risk patient and was treated with hot diathermy forceps (anticoagulation drug bridge with early re-introduction). Two occurred after esophageal resection (one EMR for papilloma and one ESD for squamous cell carcinoma in a patient with cirrhosis and varices) and were stopped by diathermic forceps during a second-look endoscopy. These four patients did not experience bleeding recurrence after the second endoscopy procedure.
Taking into account the lesion location, 2 delayed bleedings occurred in the esophagus $(2 / 8,25 \%), 1$ after ampullectomy $(1 / 3$, $33 \%), 1$ in the colorectum (1/22, $4.5 \%), 0$ in the stomach $(0 / 22,0$ $\%)$, and 0 in the duodenum $(0 / 10,0 \%)$.

According to the bleeding rate in the risky situations, 1 delayed bleeding occurred after rectal resection with early reintroduction of heparin after anticoagulant bridge strategy $(1 / 6,16.7 \%)$, and 1 in a cirrhotic patient with varices after esophageal resection $(1 / 9$, $11.1 \%$ ). No bleeding occurred under uninterrupted aspirin therapy on the 12 resections.

One patient who underwent colonoscopy with three resections of adenomas (2 EMR and 1 ESD) experienced delayed bleeding at day 1 requiring a second-look colonoscopy to treat active arterial bleeding on the only resected area where the gel was not applied. The two resected area with gel applied did not present delayed bleeding.

Among the 65 resections, the mean hemoglobin drop off 24 hours after procedure was $0.6 \mathrm{~g} / \mathrm{dL}(-0.6$ to $3.1 \mathrm{~g} / \mathrm{dL}, \mathrm{SD}: 0.8 \mathrm{~g} / \mathrm{dL})$. 


\section{Technical issues}

Gel application was always possible in the direct and retroflexed position of the scope without any difficulty. The catheter moved smoothly in the operating channel without any resistance. The mean volume of Purastat ${ }^{\circledR}$ used was $3.5 \mathrm{~mL}$ (SD: $1.4 \mathrm{~mL}$ ) in a mean time of $2.0 \mathrm{~min}$ (SD: $1.1 \mathrm{~min}$ ). Since it is a transparent gel, careful attention has to be paid to ensure complete coverage of the resection bed. On the other hand, the resection bed was always clearly visible under the gel.

\section{Adverse events}

No adverse event related to gel use was reported including allergy, acute pancreatitis, bowel occlusion or pain.

\section{Discussion}

$\nabla$

The Purastat ${ }^{\circledR}$ matrix scaffold is easy to apply, simple, and safe for endoscopic resections in the different locations of the digestive tract. In this non-comparative trial, the efficacy cannot be fully evaluated but seems promising with very few cases of delayed bleeding even for high risk patients including uninterrupted aspirin therapy, liver cirrhosis, anticoagulation drug bridges, and large duodenal resections. The rate of delayed bleedings in this study was only $6.2 \%$, although 29 patients could be considered at high risk of bleeding.

Continuous aspirin therapy is responsible for an increase in delayed bleedings from $3.2 \%$ to $16.1 \%$ after colorectal resections compared to patients with interrupted aspirin treatment [17]. In our series, among the 22 gastric resections including 2 with uninterrupted aspirin and 2 with liver cirrhosis, no delayed bleeding occurred ( $0 \%$ ). For patients with liver cirrhosis, the bleeding risk after gastric ESD is increased from $5 \%$ to $13.1 \%$ or $20 \%$ [6, 17]. This risk remains unknown in colorectal or esophageal situations for cirrhotic patients. In our series, among the 9 resections in patients with cirrhosis and portal hypertension ( 3 esophagus, 3 stomach, 2 colorectum, and 1 duodenum), one delayed bleeding occurred after esophageal ESD for squamous cell carcinoma (11.1\%). Nevertheless, the rate of bleeding in the esophagus was

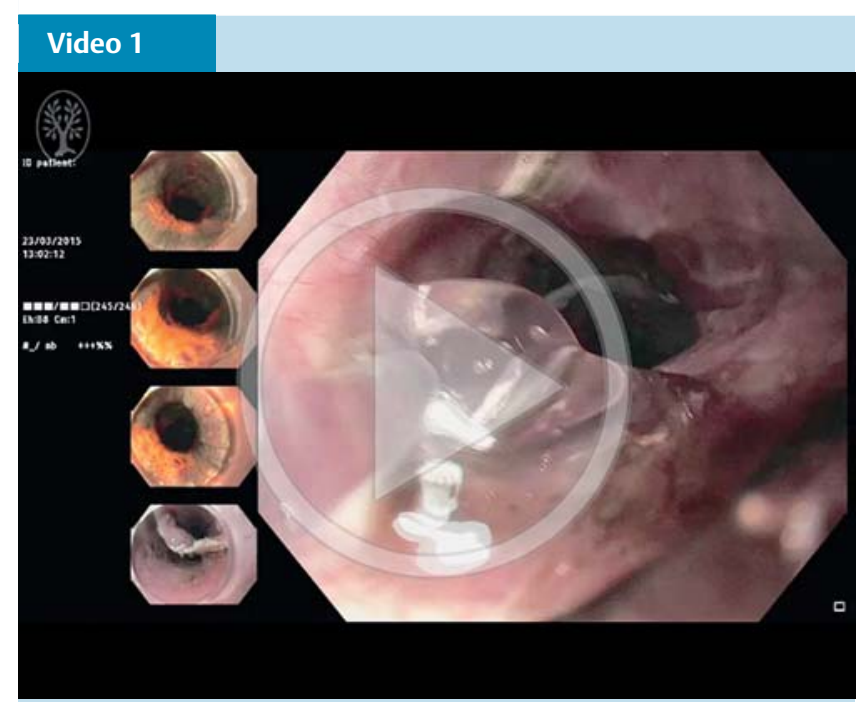

Examples of gel application in different parts of the digestive tract. Online content including video sequences viewable at: http://dx.doi.org/10.1055/s0042-102879 high in our series $(2 / 8,25 \%)$ although it is usually extremely low in the literature [18]. This high risk can partly be explained by the nature of the lesion (papilloma) for one patient and by the cirrhosis with portal hypertension for the other. Further comparative investigations are clearly required to verify the benefit of the gel in those situations.

For those high risk situations, a simple method such as a gel application could be an easy and interesting option to protect the ulcer bed from digestive secretions at the end of the procedure and only requiring an additional $2 \mathrm{~min}$. Further comparative studies are needed to evaluate the clinical benefit of such a gel. The only concern with this gel is probably its transparent appearance which makes it more difficult to cover the whole resected area with certainty. Furthermore, the gel is affected by gravity and slowly slides from the ulcer bed after covering. Exsufflation after application seems to be effective in applying the gel to the whole area with less migration. A colored gel could be easier to recognize and then to apply uniformly. On the other hand, a transparent appearance allows the resection site to be visualized below the gel.

Our study has several limitations since it is a retrospective analysis without comparison to a control group, and mixes different locations and techniques. Furthermore, repeat endoscopy to assess mucosal healing after several weeks is lacking but corresponds to clinical practice since the second-look endoscopy procedure is not recommended in routine practice in Europe.

\section{Conclusion}

\section{$\nabla$}

Use of this novel SAP gel is a quick, easy to use, and safe technique for trained physicians who perform endoscopic resections. It could help to reduce post-resection bleeding including in high risk situations. Further studies are now scheduled to fully evaluate its effectiveness and safety, particularly in higher risk situations.

\section{Competing interests: None}

\section{Institutions}

1 Endoscopy and Gastroenterology Unit, Edouard Herriot Hospital, Lyon, France 2 INSERM U1032, Lyon, France

${ }^{3}$ University Claude Bernard Lyon 1, Lyon, France

${ }^{4}$ Endoscopy and Gastroenterology Unit, Assistance Publique Hôpitaux de Paris (APHP) Cochin Hospital, Paris, France

${ }^{5}$ University Paris V Descartes, Paris, France

\section{References}

1 Tsujii Y, Nishida T, Nishiyama $O$ et al. Clinical outcomes of endoscopic submucosal dissection for superficial esophageal neoplasms: a multicenter retrospective cohort study. Endoscopy 2015; 47: 775-783

2 Koh R, Hirasawa K, Yahara $S$ et al. Antithrombotic drugs are risk factors for delayed postoperative bleeding after endoscopic submucosal dissection for gastric neoplasms. Gastrointest Endosc 2013; 78: 476-483

3 Lépilliez V, Chemaly M, Ponchon T et al. Endoscopic resection of sporadic duodenal adenomas: an efficient technique with a substantial risk of delayed bleeding. Endoscopy 2008; 40: 806-810

4 Takeuchi $Y$, Iishi $H$, Tanaka $S$ et al. Factors associated with technical difficulties and adverse events of colorectal endoscopic submucosal dissection: retrospective exploratory factor analysis of a multicenter prospective cohort. Int J Colorectal Dis 2014; 29: 1275-1284

5 Tano S, Horiki N, Omata $F$ et al. Second and third-look endoscopy for the prevention of post-ESD bleeding. Medicine (Baltimore) 2015; 94: e491 
6 Repici A, Pagano N, Hassan C et al. Endoscopic submucosal dissection of gastric neoplastic lesions in patients with liver cirrhosis: a systematic review. J Gastrointest Liver Dis 2012; 21: 303 -307

7 Ogura K, Okamoto M, Sugimoto T et al. Efficacy and safety of endoscopic submucosal dissection for gastric cancer in patients with liver cirrhosis. Endoscopy 2008; 40: 443-445

8 Basford PJ, George R, Nixon E et al. Endoscopic resection of sporadic duodenal adenomas: comparison of endoscopic mucosal resection (EMR) with hybrid endoscopic submucosal dissection (ESD) techniques and the risks of late delayed bleeding. Surg Endosc 2014; 28: $1594-1600$

9 Choi KD, Jung $H-Y$, Lee GH et al. Application of metal hemoclips for closure of endoscopic mucosal resection-induced ulcers of the stomach to prevent delayed bleeding. Surg Endosc 2008; 22: 1882 -1886

10 Liaquat H, Rohn E, Rex DK. Prophylactic clip closure reduced the risk of delayed postpolypectomy hemorrhage: experience in 277 clipped large sessile or flat colorectal lesions and 247 control lesions. Gastrointest Endosc 2013; 77: 401 - 407

11 Nieponice A, McGrath K, Qureshi I et al. An extracellular matrix scaffold for esophageal stricture prevention after circumferential EMR. Gastrointest Endosc 2009; 69: 289-296
12 Ono S, Fujishiro M, Yoshida $N$ et al. Thienopyridine derivatives as risk factors for bleeding following high risk endoscopic treatments: Safe Treatment on Antiplatelets (STRAP) study. Endoscopy 2015; 47: 632 637

13 Masuhara H, Fujii T, Watanabe Y et al. Novel infectious agent-free hemostatic material (TDM-621) in cardiovascular surgery. Ann Thorac Cardiovasc Surg 2012; 18: 444-451

14 Yoshida M, Goto N, Kawaguchi M et al. Initial clinical trial of a novel hemostat, TDM-621, in the endoscopic treatments of the gastric tumors. J Gastroenterol Hepatol 2014; 29: 77 - 79

15 Tuthill DD, Bayer V, Gallagher AM et al. Assessment of topical hemostats in a renal hemorrhage model in heparinized rats. J Surg Res 2001; 95: $126-132$

$16 \mathrm{Wu} M, Y e Z, Z h u H$ et al. Self-assembling peptide nanofibrous hydrogel on immediate hemostasis and accelerative osteosis. Biomacromolecules 2015; 16: $3112-3118$

17 Ninomiya Y, Oka S, Tanaka S et al. Risk of bleeding after endoscopic submucosal dissection for colorectal tumors in patients with continued use of low-dose aspirin. J Gastroenterol 2015; 50: 1041 - 1046

18 Tsujii $Y$, Nishida T, Nishiyama $O$ et al. Clinical outcomes of endoscopic submucosal dissection for superficial esophageal neoplasms: a multicenter retrospective cohort study. Endoscopy 2015; 47: 775 - 783 